\title{
A latent structural analysis of health behaviors among people living with spinal cord injury
}

\author{
Chao $\mathrm{Li}^{1} \cdot$ Nicole D. DiPiro ${ }^{1} \cdot$ James S. Krause ${ }^{1}$
}

Received: 25 July 2017 / Revised: 21 September 2017 / Accepted: 1 October 2017 / Published online: 30 November 2017

(c) International Spinal Cord Society 2018

\begin{abstract}
Study design Cross-sectional study.

Objectives To develop a latent structural model of health behaviors among people with spinal cord injury (SCI) that accounts for measurement of underlying factors and their association with demographic and injury-related variables.

Setting The data were collected at a large specialty hospital and analyzed at a medical university in the Southeastern United States.

Methods A total of 1871 participants with traumatic SCI of at least 1-year duration were included. Exploratory factor analysis (EFA) was used to identify the latent health behavior structures. Several key exogenous variables were also linked with the latent health behavior factors.

Results Five latent health behavior factors were identified by the EFA with excellent model fit (root mean square error of approximation $=0.043$ ). These latent factors included (1) medication non-compliance, (2) prescription medication and substance use, (3) smoking, (4) alcohol consumption, and (5) healthy lifestyle activities and participation. Sex, race/ ethnicity, age, years since injury, and injury severity were all significantly associated with at least one latent health behavior factor. For instance, men scored higher in smoking and alcohol consumption, whereas women scored higher in prescription medication and substance use. Non-whites scored higher on the medication non-compliance dimension and lower on the healthy lifestyle activities and participation dimension.

Conclusions Utilization of latent health behavior factors provides more stable and comprehensive composite scores than does a single observed health behavior indicator. There are important differences in behaviors based on individual characteristics.
\end{abstract}

\section{Introduction}

Spinal cord injury (SCI) is associated with an increased risk of secondary health conditions [1,2] and mortality [3-5]. Attenuating the risk and promoting longevity after injury requires an understanding of the underlying risk and protective factors. It is particularly important to study modifiable risk factors, such as smoking, alcohol misuse, and physical inactivity, so that appropriate prevention and intervention strategies can be developed.

The Theoretical Risk and Prevention Model (TRPM) developed by Krause et al. [6, 7] outlines the predictive

Chao Li

licha@musc.edu

1 College of Health Professions, Medical University of South Carolina, Charleston, SC, USA relationships between five levels of factors: (1) biographic and injury, (2) psychological and environmental, (3) behavioral, (4) secondary conditions, and (5) mortality. Modifiable health behaviors are the most direct predictors of secondary health conditions, which are in turn predictive of mortality. As such, a substantial line of large-scale research has focused on classifying the risk and protective relationships between behavioral factors and health outcomes and mortality after SCI [8-15].

Studies of mortality have identified several behavioral risk factors, including smoking, binge drinking, and prescription medication misuse $[10-12,16]$. These behavioral risk factors have been associated with secondary health conditions such as fatigue [13], pressure ulcers [14, 17, 18], depression [19, 20], and urinary tract issues [21], and also hospitalizations after SCI $[9,22]$. A number of protective health behaviors, including healthy diet, physical activity and exercise, and participation, have also been identified $[8,11,15,17]$. 
It is important to understand how behavioral risk and protective factors relate to each other, to identify common dimensions so that they can be measured efficiently, and to identify how behaviors co-vary as a function of SCI and demographic characteristics, the most fundamental predictive factors. A previous analysis implemented latent variable structural equation modeling (SEM) and identified seven specific health behaviors (healthy nutrition, unhealthy nutrition, fitness, smoking, alcohol use, psychotropic prescription medications, and SCI healthy activities) and their relationships with specific demographic and injury-related characteristics [8]. Several significant correlations between demographic and injury factors and the behavioral domains were observed, and distinct underlying risk and protective dimensions were identified. This research establishes a measurement model for several health behavioral dimensions, laying a foundation for its use in relation to secondary health conditions. Continued research is needed to validate behavioral measures and to identify additional behavioral dimensions to aid the development of interventions for prevention and treatment of secondary health conditions and mortality after SCI.

\section{Purpose}

Our purpose was to extend the earlier research [8], using the data from a new and expanded assessment with a larger participant cohort, to identify latent structures of health behaviors and evaluate their relationships with several key exogenous demographic and injury variables. The modified set of behavioral factors included greater detail regarding medication compliance and illicit drug use, whereas some well-established behavioral item sets from earlier research, including nutrition and SCI-specific behaviors, were not replicated to limit overlap and minimize participant burden. The data analytic method followed the blueprint from a similar analysis directed at health outcomes [23].

\section{Methods}

\section{Participants}

All the participants were identified and recruited from a large specialty hospital in the Southeastern United States as a part of the SCI Longitudinal Health Study, which has been described in detail in a previous study. The inclusion criteria were (1) 18 years or older, (2) at least 1 year after traumatic SCI, and (3) residual SCI deficits (corresponding to American Spinal Injury Association Impairment Scale AD). Institutional Review Board approval was obtained before the data were collected. A total of 1871 eligible participants enrolled in the most recent follow-up were included in this analysis. Two cohorts comprised the 1871 participants: 625 participants who were utilized in an earlier study of behavioral factors and a new cohort of 1246 participants.

\section{Procedures}

Introductory cover letters were mailed to the participants describing the SCI Longitudinal Health Study and informing them of forthcoming study materials. The self-report assessments (SRA) were mailed 4-6 weeks later. Up to three mails and a follow-up phone call were used to maximize the participation. The participants were offered $\$ 50$ in remuneration. A more complete description of the data collection procedures and participant selection appears elsewhere [15, 24].

\section{Measures}

A comprehensive SRA including questions on health behaviors and exogenous predictors (e.g. demographic and injury factors) was administered to all the participants. The measurement sets included behavioral items from the CDC Behavioral Risk Factor Surveillance System (BRFSS) [25], World Health Organization (WHO), Alcohol, Smoking, and Substance Involvement Screening Test (ASSIST) [26], Craig Hospital Assessment and Reporting Technique (CHART) [27, 28], and some items developed specifically for the SCI Longitudinal Health Study, many dating back to the beginning stage of the study from 1997 to 1998 . The selection of health behaviors incorporated into the SRA was based on the TRPM [6, 7], developed to guide the selection of predictors for health outcomes, as well as by those identified as important in previous research.

The demographic and injury-related items included sex, age, and race/ethnicity (non-Hispanic whites and nonwhites). The injury characteristics included years since injury and injury severity, categorized using a combination of injury level and ambulatory status. All ambulatory participants were included in one group (regardless of injury level) and those who were non-ambulatory were grouped as follows: C1-C4, C5-C8, and non-cervical.

The BRFSS is a standardized instrument developed and implemented by the CDC to monitor basic health behaviors in the United States general population [25]. We included BRFSS items to measure alcohol consumption and smoking behaviors. For alcohol consumption, we used four items: (1) number of drinking days with less than five or more drinks on one occasion in the past 30 days, (2) number of drinks on average on drinking days, (3) number of times having five or more drinks on one occasion in the past 30 days, and (4) number of most drinks on any occasion in the past 30 days. For smoking, the participants were asked multiple questions 
about smoking history, including two used in the current analysis (others were collinear). The first smoking question asked "how many cigarettes do you currently smoke per day?", and was measured on a 5-point scale as none at all, 1-9 (<1/2 a pack), 10-19 (<1 pack), 20-40 (1-2 packs), and $41+$ (more than 2 packs). The second smoking question asked at what age the participants first began to smoke on a regular basis (everyday). This item was grouped into five categories as never, $\geq 22$ years old, 19-21 years old, 15-18 years old, and $<15$ years old, coded as 1 to 5 , respectively.

Three groups of substance use questions were selected from the WHO ASSIST [26]. The participants were asked "How often have you used the following substances for which you did not have a prescription?". The selected substances included cannabis (marijuana, pot, grass, hash, etc.), sedatives or sleeping pills (Valium, Serepax, Rohypnol, etc.), and opioids (heroin, morphine, methadone, codeine, etc.). The responses to these three questions were scored on a 5-point scale (never, once or twice, monthly, weekly, and daily/almost daily).

The frequency of prescription medication usage was measured for conditions where medications may have psychotropic effects. The participants were asked about how frequently (never, sometimes, weekly, and daily) they used medications for pain, spasticity, depression, and sleep. The specific medications were not identified.

Four medication compliance-related items were developed specifically for this stage of the SCI Longitudinal Health Study. They included (1) I stop taking a medication when I start feeling better, rather than taking them until they are gone, (2) I forget to take my medication on time, (3) I skip prescribed doses of one or more of my medications, and (4) I take my medications in the dosage and at the times the doctor has prescribed. Each item had five response categories: never, occasionally, sometimes, often, and always.

A series of healthy activity and participation-related items were also developed. The overall fitness was measured on a 5-point scale (poor, fair, good, very good, and excellent). The frequency of planned exercise was grouped into six categories (rarely, once per month, 2-3 times per month, 1-2 times per week, 3-4 times per week, and 5 or more times per week). The participants also responded to questions from the CHART, including "how many days do you get out of your house and go somewhere in a typical week?" and "how many hours are you out of bed on a typical day?" [27, 28]. Additionally, they were asked a series of questions from the CHART relating to productive activities, including how many hours per week they spent in schoolwork, homemaking, home maintenance, volunteer work, and recreational activities. Finally, we asked the participants (1) about their working hours per week, (2) whether they had a flu shot in the past 12 months (yes or no), and (3) how healthy their diet was, in general (poor, fair, good, very good, or excellent).

\section{Statistical analysis}

Exploratory factor analysis (EFA) was used to define the latent structures of health behaviors, which cannot be directly measured, but can be inferred from a number of observed variables that can be directly measured. EFA is a widely used method to reduce a large number of variables to a smaller set of summary variables and discover the underlying theoretical structure and the relationships among measured variables. The relationships between the latent structures of health behaviors and several key exogenous variables (variables independent of factors extracted from EFA) were evaluated by SEM. These exogenous variables included sex (ref $=$ women), race/ethnicity (ref $=$ non-Hispanic white), chronologic age, years since injury, and injury severity (ref = ambulatory).

All descriptive analyses were performed by SAS (Version 9.4) [29]. We used M-plus (Version 7.4) [30] for all SEM analyses. The model fit was evaluated by $\chi^{2}$, comparative fit index (CFI), Tucker Lewis index (TLI), and root mean square error of approximation (RMSEA). The CFI and $\mathrm{T}$ LI with values of $>0.95$ indicate a good match between the data and the hypothesized model. RMSEA of $<0.05$ suggests excellent model fit, and 0.05-0.08 indicates good fit [31]. For EFA, a minimum of three items is set to produce stable factors with adequate internal consistency. Only items with loadings $>0.30$ during the EFA are retained in the SEM with exogenous variables.

The continuous variables were demonstrated by mean and standard deviation, and the categorical variables were shown as frequency and percentage.

\section{Statement of ethics}

We certify that all the applicable institutional and governmental regulations concerning the ethical use of human volunteers were followed during the course of this research.

\section{Results}

\section{Descriptive}

The majority of participants were non-Hispanic white (74.4\%) and men (74.5\%). The average chronological age was $48.3(\mathrm{SD}=13.3)$ and time since $\mathrm{SCI}$ was 15.9 years $(\mathrm{SD}=10.1)$. Thirty-five percent were classified as having a non-cervical, non-ambulatory SCI, followed by ambulatory SCI (29.7\%), C5-C8 non-ambulatory SCI (25.5\%), and C1-C4 non-ambulatory SCI (9.9\%) (Table 1$)$. 
Table 1 Demographic characteristics

\begin{tabular}{|c|c|c|}
\hline & $n$ & $\%$ \\
\hline \multicolumn{3}{|l|}{ Sex } \\
\hline Men & 1394 & 74.5 \\
\hline Women & 447 & 25.5 \\
\hline \multicolumn{3}{|l|}{ Race } \\
\hline White & 1386 & 74.4 \\
\hline Black & 406 & 21.8 \\
\hline Others & 71 & 3.8 \\
\hline \multicolumn{3}{|l|}{ Chronologic age } \\
\hline$<40$ & 515 & 27.5 \\
\hline $40-49$ & 491 & 26.2 \\
\hline $50-59$ & 459 & 24.5 \\
\hline $60-69$ & 300 & 16.0 \\
\hline $70+$ & 106 & 5.7 \\
\hline \multicolumn{3}{|l|}{ Years post-injury } \\
\hline$<20$ & 1296 & 69.3 \\
\hline $20-29$ & 402 & 21.5 \\
\hline $30-39$ & 119 & 6.4 \\
\hline $40-49$ & 41 & 2.2 \\
\hline $50+$ & 11 & 0.6 \\
\hline \multicolumn{3}{|l|}{ Injury severity } \\
\hline Non-ambulatory: C1-C4 & 183 & 9.9 \\
\hline Non-ambulatory: C5-C8 & 469 & 25.5 \\
\hline Non-ambulatory: non-cervical & 643 & 34.9 \\
\hline Ambulatory & 547 & 29.7 \\
\hline
\end{tabular}

\section{Exploratory factor analysis}

Five latent behavioral factors were extracted from the EFA $($ RMSEA $=0.043)$. The detailed rotated factor loadings are demonstrated in Table 2. Factor 1, entitled medication noncompliance, comprised four variables related to proper use of prescribed medications. Factor 2, medication and substance use, comprised seven variables that included pain, spasticity, sleep and depression medication use, use of sedatives or sleeping pills (Valium, Serepax, Rohypnol, etc.), and use of opioids (heroin, morphine, methadone, codeine, etc.). Factors 3 and 4 measured smoking and alcohol consumption behaviors. Factor 5 appeared to be specific to healthy lifestyle activities and participation, including days out of house and hours out of bed, fitness level, planned exercise, diet, and hours in home maintenance and recreational activities.

\section{Latent SEM}

$Z$-scores were converted for the five factors extracted from the EFA. We created dummy variables for sex, race/ethnicity, and injury severity to identify the relationship between the demographic and the injury-related characteristics and the five latent behavioral factors $\left(\mathrm{RMSEA}=0.052 ; \chi^{2}=\right.$ 1995.597, $\quad \mathrm{DF}=346, \quad p<0.001 ; \quad \mathrm{CFI}=0.852 ; \quad \mathrm{TLI}=$ $0.823)$. Table 3 is a summary of the full latent SEM. For interpretation, higher scores (i.e., positive values) for the risk health behaviors (medication non-compliance, medication and substance use, smoking, and alcohol consumption) indicate greater risk behaviors for the referent group; whereas, negative values indicate less risky behaviors. For the protective health behavior (healthy lifestyle and participation), negative associations indicate less healthy behaviors.

Compared to men, women scored higher on the medication and substance use dimensions. Women had lower scores on the alcohol consumption, smoking, and healthy lifestyle activities and participation dimensions. Race/ethnicity was significantly associated with two dimensions. Nonwhites scored higher on the medication non-compliance dimension and lower on the healthy lifestyle activities and participation dimension. Age was significantly associated with each behavior. With increasing age, medication noncompliance, alcohol consumption, smoking, and healthy lifestyle and participation decreased. Medication and substance use was higher among those who were older.

Regarding SCI-related exogenous variables, longer duration of SCI was associated with lower scores on the medication and substance use dimension and higher scores on the alcohol consumption dimension. Four dimensions were significantly associated with injury severity. Those with cervical injuries (non-ambulatory) had lower scores on medication non-compliance. Compared to the ambulatory reference group, non-ambulatory participants reported higher scores of medication and substance use and lower scores on alcohol consumption and healthy lifestyle activities and participation.

\section{Discussion}

The unique contribution of this study was the identification of five underlying dimensions of health behaviors and their relationships with important participant characteristics. This builds upon and extends earlier work, which first identified seven behavioral dimensions, using a larger participant cohort and inclusion of a modified set of health behaviors [8]. The new key findings include the identification of a behavioral domain related to medication compliance and the integration of the domain of prescription medication use with that of an illicit drug use. The differential patterns of behaviors as a function of injury and demographic characteristics help us to understand the patterns of behaviors among the participants with different types of characteristics. 
Table 2 Promax rotated loadings of health behaviors from exploratory factor analysis using full sample $($ RMSEA $=0.043)$

\begin{tabular}{|c|c|c|c|c|c|}
\hline \multirow[t]{2}{*}{ Variable } & $\begin{array}{l}\text { Medication } \\
\text { non-compliance }\end{array}$ & $\begin{array}{l}\text { Medication and } \\
\text { substance use }\end{array}$ & Smoking & $\begin{array}{l}\text { Alcohol } \\
\text { consumption }\end{array}$ & $\begin{array}{l}\text { Healthy lifestyle } \\
\text { activities and } \\
\text { participation }\end{array}$ \\
\hline & \multicolumn{5}{|c|}{ Promax rotated loadings } \\
\hline Stop meds when feel better & $0.579^{\mathrm{a}}$ & -0.017 & 0.008 & 0.046 & 0.028 \\
\hline Forget meds on time & $0.687^{\mathrm{a}}$ & 0.096 & -0.080 & 0.020 & 0.070 \\
\hline Skip prescribed doses & $0.917^{\mathrm{a}}$ & 0.141 & -0.181 & 0.029 & 0.088 \\
\hline Take meds as prescribed & $-0.565^{\mathrm{a}}$ & 0.065 & 0.031 & 0.003 & -0.050 \\
\hline Pain meds & 0.139 & $0.635^{\mathrm{a}}$ & 0.004 & -0.073 & 0.012 \\
\hline Spasticity meds & -0.056 & $0.537^{\mathrm{a}}$ & -0.110 & -0.040 & 0.021 \\
\hline Sleep meds & 0.064 & $0.707^{\mathrm{a}}$ & -0.010 & 0.009 & -0.042 \\
\hline Depression meds & 0.094 & $0.567^{\mathrm{a}}$ & 0.004 & -0.023 & 0.055 \\
\hline Working hours/week & -0.039 & $0.635^{\mathrm{a}}$ & 0.082 & 0.092 & -0.115 \\
\hline Sedatives & 0.163 & $0.550^{\mathrm{a}}$ & 0.252 & 0.039 & -0.034 \\
\hline Opioids, heroin, etc. & -0.200 & $0.126^{\mathrm{a}}$ & 0.647 & -0.019 & 0.036 \\
\hline Age first smoke & -0.164 & 0.038 & $0.934^{\mathrm{a}}$ & 0.015 & 0.149 \\
\hline Number of cigarettes/day & 0.060 & 0.073 & $0.446^{\mathrm{a}}$ & 0.155 & -0.046 \\
\hline Cannabis & 0.016 & 0.005 & $0.026^{\mathrm{a}}$ & 0.935 & 0.001 \\
\hline Average drink & 0.023 & 0.031 & 0.001 & $0.665^{\mathrm{a}}$ & 0.108 \\
\hline Five or more drinks on one occasion & 0.035 & -0.016 & 0.017 & $0.947^{\mathrm{a}}$ & -0.077 \\
\hline Most drinks on any occasion & 0.094 & -0.200 & -0.070 & $0.085^{\mathrm{a}}$ & -0.398 \\
\hline Get out of house & 0.120 & -0.248 & -0.008 & 0.019 & $-0.425^{\mathrm{a}}$ \\
\hline Hours out of bed & -0.211 & -0.060 & -0.069 & 0.073 & $-0.584^{\mathrm{a}}$ \\
\hline Fitness & -0.131 & 0.146 & -0.110 & 0.000 & $-0.649^{\mathrm{a}}$ \\
\hline Planned exercise & -0.244 & 0.040 & -0.196 & 0.038 & $-0.446^{\mathrm{a}}$ \\
\hline Diet & 0.163 & -0.009 & 0.205 & -0.133 & $-0.361^{\mathrm{a}}$ \\
\hline Hours per week in home maintenance & -0.010 & 0.178 & 0.022 & -0.019 & $-0.504^{\mathrm{a}}$ \\
\hline Hours per week in recreational activities & -0.003 & -0.041 & -0.043 & 0.289 & $-0.198^{\mathrm{a}}$ \\
\hline Days of non-binge drinking & 0.053 & -0.021 & 0.015 & 0.078 & -0.061 \\
\hline Hours per week in school & 0.177 & -0.111 & 0.208 & -0.161 & -0.281 \\
\hline Hours per week in homemaking & 0.114 & 0.057 & -0.132 & -0.058 & -0.249 \\
\hline Hours per week in volunteer work & -0.072 & 0.215 & -0.252 & -0.051 & 0.027 \\
\hline Flu shot & 0.579 & -0.017 & 0.008 & 0.046 & 0.028 \\
\hline
\end{tabular}

${ }^{a} \geq 0.30$

The current EFA identified five health behavior dimensions: medication non-compliance, medication and substance use, smoking, alcohol consumption, and healthy lifestyle activities and participation. There are some key similarities and differences with the earlier analysis, which identified seven specific behavioral domains. First, three of the domains are similar to those previously identified including smoking, alcohol consumption, and healthy lifestyle activities and participation. The smoking dimension is refined by utilizing age at which the individual first smoked as one of the behaviors, reducing co-linearity. The medication compliance domain is unique, based on newly added items, whereas substance misuse represents a refinement from the previous research as it includes both prescription and illicit drug use. If an investigator's intention is restricted to prescription medication use, then the previously identified domain is still valid; whereas, if the intention is to measure broader substance misuse, then the current inclusion of legal and illicit drugs will provide a viable option. Three previously identified domains, including healthy and unhealthy nutrition, and SCI healthy activities, were not assessed in the current study; yet they remain as viable options for an investigator interested in these domains.

Interesting associations were observed between the demographic factors (gender, age, and race/ethnicity) and health behaviors. Gender was significantly associated with medication and substance use, smoking, alcohol consumption, and healthy lifestyle activities and participation. 
Table 3 Latent model identifying the relationships between the five factors and demographic and injury characteristics $($ RMSEA $=0.052)$

\begin{tabular}{|c|c|c|c|c|}
\hline & Estimate $^{\mathrm{a}}$ & $\mathrm{SE}^{\mathrm{b}}$ & Est./SE ${ }^{\mathrm{c}}$ & StdYX $X^{d}$ \\
\hline \multicolumn{5}{|l|}{ Medication non-compliance } \\
\hline Gender (women) & 0.066 & 0.041 & 1.605 & 0.048 \\
\hline $\begin{array}{l}\text { Non-ambulatory: } \\
\mathrm{C} 1-\mathrm{C} 4\end{array}$ & -0.264 & 0.064 & $-0.104^{+++}$ & -0.132 \\
\hline $\begin{array}{l}\text { Non-ambulatory: } \\
\text { C5-C8 }\end{array}$ & -0.202 & 0.049 & $-0.155^{+++}$ & -0.146 \\
\hline $\begin{array}{l}\text { Non-ambulatory: non- } \\
\text { cervical }\end{array}$ & -0.013 & 0.044 & -0.300 & -0.010 \\
\hline Years since injury & 0.002 & 0.002 & 1.105 & 0.035 \\
\hline Age & -0.009 & 0.001 & $-0.057^{+++}$ & -0.198 \\
\hline Race (non-white) & 0.107 & 0.040 & $2.708^{++}$ & 0.078 \\
\hline \multicolumn{5}{|c|}{ Medication and substance use } \\
\hline Gender (women) & 0.178 & 0.047 & $3.753^{+++}$ & 0.109 \\
\hline $\begin{array}{l}\text { Non-ambulatory: } \\
\text { C1-C4 }\end{array}$ & 0.383 & 0.077 & $4.992^{+++}$ & 0.162 \\
\hline $\begin{array}{l}\text { Non-ambulatory: } \\
\text { C5-C8 }\end{array}$ & 0.198 & 0.059 & $3.353^{+++}$ & 0.121 \\
\hline $\begin{array}{l}\text { Non-ambulatory: non- } \\
\text { cervical }\end{array}$ & 0.104 & 0.054 & 1.919 & 0.069 \\
\hline Years since injury & -0.013 & 0.002 & $-0.716^{+++}$ & -0.184 \\
\hline Age & 0.007 & 0.002 & $3.949^{+++}$ & 0.125 \\
\hline Race (non-white) & -0.042 & 0.050 & -0.836 & -0.026 \\
\hline \multicolumn{5}{|l|}{ Smoking } \\
\hline Gender (women) & -0.208 & 0.051 & $-4.064^{+++}$ & -0.138 \\
\hline $\begin{array}{l}\text { Non-ambulatory: } \\
\text { C1-C4 }\end{array}$ & -0.115 & 0.075 & -1.529 & -0.053 \\
\hline $\begin{array}{l}\text { Non-ambulatory: } \\
\text { C5-C8 }\end{array}$ & -0.105 & 0.057 & -1.852 & -0.069 \\
\hline $\begin{array}{l}\text { Non-ambulatory: non- } \\
\text { cervical }\end{array}$ & -0.022 & 0.053 & -0.420 & -0.016 \\
\hline Years since injury & 0.004 & 0.002 & 1.582 & 0.057 \\
\hline Age & -0.012 & 0.002 & $-6.035^{+++}$ & -0.233 \\
\hline Race (non-white) & -0.056 & 0.050 & -1.109 & -0.037 \\
\hline \multicolumn{5}{|l|}{ Alcohol consumption } \\
\hline Gender (women) & -0.552 & 0.118 & $-4.660^{+++}$ & -0.146 \\
\hline $\begin{array}{l}\text { Non-ambulatory: } \\
\text { C1-C4 }\end{array}$ & -0.767 & 0.158 & $-4.846^{+++}$ & -0.140 \\
\hline $\begin{array}{l}\text { Non-ambulatory: } \\
\text { C5-C8 }\end{array}$ & -0.357 & 0.111 & $-3.228^{++}$ & -0.094 \\
\hline $\begin{array}{l}\text { Non-ambulatory: non- } \\
\text { cervical }\end{array}$ & -0.211 & 0.101 & $-2.099^{+}$ & -0.061 \\
\hline Years since injury & 0.011 & 0.005 & $2.306^{+}$ & 0.065 \\
\hline Age & -0.034 & 0.004 & $-8.543^{+++}$ & -0.267 \\
\hline Race (non-white) & -0.152 & 0.092 & -1.648 & -0.040 \\
\hline \multicolumn{5}{|c|}{ Healthy lifestyle activities and participation } \\
\hline Gender (women) & -0.382 & 0.080 & $-4.805^{+++}$ & -0.138 \\
\hline \multirow[t]{2}{*}{$\begin{array}{l}\text { Non-ambulatory: } \\
\text { C1-C4 }\end{array}$} & -1.128 & 0.133 & $-8.501^{+++}$ & -0.280 \\
\hline & -0.653 & 0.099 & $-6.583^{+++}$ & -0.234 \\
\hline
\end{tabular}

Table 3 (continued)

\begin{tabular}{lllll}
\hline & Estimate $^{\mathrm{a}}$ & $\mathrm{SE}^{\mathrm{b}}$ & Est./SE $^{\mathrm{c}}$ & StdYX $^{\mathrm{d}}$ \\
\hline $\begin{array}{l}\text { Non-ambulatory: } \\
\text { C5-C8 }\end{array}$ & & & & \\
$\quad$ Non-ambulatory: non- & -0.404 & 0.089 & $-4.520^{+++}$ & -0.158 \\
cervical & & & & \\
$\quad$ Years since injury & -0.002 & 0.004 & -0.512 & -0.015 \\
$\quad$ Age & -0.006 & 0.003 & $-2.316^{+}$ & -0.070 \\
Race (non-white) & -0.293 & 0.076 & $-3.873^{+++}$ & -0.105 \\
\hline
\end{tabular}

DF degree of freedom

Note: Each of the injury severity categories $(\mathrm{C} 1-\mathrm{C} 4, \mathrm{C} 5-\mathrm{C} 8$, and noncervical) was compared against a fourth category of all ambulatory cases

${ }^{\text {a } M o d e l ~ e s t i m a t e d ~ v a l u e ~ f o r ~ e a c h ~ p a r a m e t e r ~}$

${ }^{\mathrm{b}}$ Standard errors of the parameter estimates

${ }^{\mathrm{c}}$ Value of the parameter estimate divided by the standard error $(t$ value). Values $>1.96$ are statistically significant at ${ }^{+} p<0.05,>2.58$ are significant at ${ }^{++} p<0.01$, and $>3.29$ are significant at ${ }^{+++} p<$ 0.001

${ }^{\mathrm{d}}$ Uses the variances of the continuous latent variables and of the background and outcome variables for standardization (standardized regression coefficient)

Consistent with smoking and drinking statistics from the general population [32,33], it appears that the women in our sample smoke and drink less than men, yet tended to have more medication and substance use issues than men. Consistent with earlier research [8], age was related to each of the behavioral dimensions, with negative correlations observed for healthy lifestyle activities and participation, smoking, and alcohol consumption. Unique to this analysis, older age was associated with improved medication compliance but also increased medication and substance use. While non-white classification was previously positively associated with SCI healthy activities and negatively associated with unhealthy diets [8], we found that non-whites indicated less healthy lifestyle activities and participation, as well as greater medication non-compliance.

Injury characteristics, time since injury and severity of injury, were associated with all of the health behaviors except smoking. Previous research found that injury severity (non-ambulatory) was negatively associated with alcohol use, fitness, and smoking, and positively correlated with prescription medication use and SCI healthy activities [8]. However, we found no association between severity and smoking. The individuals with cervical-level injuries (non-ambulatory) were more likely to report medication compliance. Our findings that non-ambulatory participants reported higher levels of medication and substance use and lower levels of healthy lifestyle activities and participation and alcohol consumption were consistent with the previous research. Years since injury was not previously assessed 
and this oversight was addressed in the current study. Our sample is unique in that the participants were on an average $16 \pm 10$ years post-injury. We found that with increased time since injury, medication and substance use decreased, and alcohol consumption increased.

\section{Clinical implications}

The modifiable health behaviors such as smoking, alcohol consumption, physical inactivity, prescription medication use, and diet have been identified as risk factors for secondary health conditions $[8,24]$ and mortality $[10,11,16]$. The modifiable health behaviors identified in the EFA present unique opportunities for targeted interventions and prevention strategies, aimed at improving health and longevity after SCI. Further, the demonstrated relationships with participant characteristics highlight those who may benefit most.

Our findings suggest that there are differences in behavioral dimensions according to demographic and injury factors. This information will be useful to consider in rehabilitation research and clinical practice to increase awareness and assist in developing targeted interventions to improve the modifiable health behaviors. It would be beneficial to consider individual characteristics and treat health behaviors as groups or clusters, rather than focusing on a single health behavior. For example, the latent health behavior "healthy activities and participation" included the items planned exercise and fitness level, as well as diet and other participation-related items. Ample evidence shows that exercise and physical activity are important for reducing morbidity and mortality [34-36], and our findings suggest that it might be important to also consider healthy diet and participation and address the behaviors together. Further, our analysis suggests that the individuals who are older, non-ambulatory, of minority status, and female are less likely to report these healthy behaviors. Taking the findings into consideration, rehabilitation researchers and exercise professionals might address the cluster of health behaviors and focus on individuals with the aforementioned characteristics in order to improve the overall healthy behaviors, and in turn reduce adverse health outcomes. Intervening and addressing multiple health behaviors in the same cluster may trigger a multiplicative and synergistic effect, which may maximize the effect of the intervention.

\section{Limitations}

This study has several noteworthy limitations. First, all the data were collected by SRA, which was subject to recall bias. We attempted to minimize the influence of recall bias by asking the participants to recall their activities on a daily basis or in the past month or year. However, there was no evidence to show the extent to which the recall bias influenced the findings of this study. Second, our participants were recruited from a specialty hospital, not a population-based registry. Although this is the most frequent source of recruitment in SCI studies, including the SCI Model Systems, it limits the generalizability of our findings. Third, although we intended to include as many important health behaviors as possible, there are likely other health behaviors not identified in our SRA. For instance, nutrition was the focus of an earlier study, hence was not replicated. Those behavioral domains identified in the earlier research remain valid, but we could not specifically link them with the domains we observed in the current study. Additionally, there are limitations regarding the SRA questions of general activities. The self-report measures of general activities should not be used when a study has the opportunity to collect more detailed information. For this study, the fitness and exercise questions were limited and do not address the SCI physical activity guidelines [37], which were developed after the SRA. While our purpose was to gain global information on fitness and exercise, more specific research is needed, including intervention and observational studies which assess guideline-driven levels of activity as a protective health behavior. Fourth, this study was designed as a cross-sectional study, which does not allow us to draw causal conclusions about the longitudinal associations between these five latent health behavioral factors and the exogenous variables, although SEM is developed to explain causal relationship to some extent.

\section{Future research}

There is a need to monitor the change in behavioral health factors over time and identify if, and to what extent, these changes are related with exogenous demographic and injury-related characteristics. Continued study of demographic and injury factors in relation to behavioral factors will help to identify patterns of change over time. It is also important to investigate behaviors in relation to other important parameters within the TRPM, including psychological variables such as self-efficacy and coping. The five health behavior factors identified, along with behavioral factors identified in the previous research [8], should be linked with latent health outcome dimensions [23, 38] to evaluate cross-sectional and longitudinal relationships. This will establish a greater foundation for the development of prevention strategies.

\section{Conclusion}

We identified five latent health behavior factors and found significant associations with demographic and injury-related characteristics. Identification of these five underlying 
dimensions of health behaviors added to and improved our knowledge of the structure of health behaviors among people living with SCI.

Acknowledgements The contents of this publication were developed under a grant from the National Institute on Disability, Independent Living, and Rehabilitation Research (NIDILRR grant number 90RT5003). NIDILRR is a Center within the Administration for Community Living (ACL), Department of Health and Human Services (HHS). The contents of this publication do not necessarily represent the policy of NIDILRR, ACL, HHS, and you should not assume endorsement by the Federal Government.

\section{Compliance with ethical standards}

Competing interests The authors declare that they have no competing interests.

\section{References}

1. Jensen MP, Molton IR, Groah SL, Campbell ML, Charlifue S, Chiodo A, et al. Secondary health conditions in individuals aging with SCI: terminology, concepts and analytic approaches. Spinal Cord. 2012;50:373-8.

2. Rimmer JH, Chen MD, Hsieh K. A conceptual model for identifying, preventing, and managing secondary conditions in people with disabilities. Phys Ther. 2011;91:1728-39.

3. Chamberlain JD, Meier S, Mader L, von Groote PM, Brinkhof MW. Mortality and longevity after a spinal cord injury: systematic review and meta-analysis. Neuroepidemiology. 2015;44:182-98.

4. Shavelle RM, DeVivo MJ, Brooks JC, Strauss DJ, Paculdo DR. Improvements in long-term survival after spinal cord injury? Arch Phys Med Rehabil. 2015;96:645-51.

5. Krause JS, Cao Y, DeVivo MJ, DiPiro ND. Risk and protective factors for cause-specific mortality after spinal cord injury. Arch Phys Med Rehabil. 2016;97:1669-78.

6. Krause JS. Secondary conditions and spinal cord injury: a model for prediction and prevention. Top Spinal Cord Inj Rehabil. 1996;2:217-27.

7. Krause JS, Saunders LL, DiPiro ND, Reed KS. Theoretical risk and prevention model for secondary health conditions and mortality: 15 years of research. Top Spinal Cord Inj Rehabil. 2013;19:15-24.

8. Krause JS, McArdle JJ, Pickelsimer E, Reed KS. A latent variable structural path model of health behaviors after spinal cord injury. J Spinal Cord Med. 2009;32:162-74.

9. Krause JS, Saunders LL. Risk of hospitalizations after spinal cord injury: relationship with biographical, injury, educational, and behavioral factors. Spinal Cord. 2009;47:692-7.

10. Krause JS, Carter RE, Pickelsimer E. Behavioral risk factors of mortality after spinal cord injury. Arch Phys Med Rehabil. 2009;90:95-101.

11. Krause JS, Saunders LL. Risk of mortality and life expectancy after spinal cord injury: the role of health behaviors and participation. Top Spinal Cord Inj Rehabil. 2010;16:53-60.

12. Krause JS, Saunders LL. Socioeconomic and behavioral risk factors for mortality: do risk factors observed after spinal cord injury parallel those from the general USA population? Spinal Cord. 2012;50:609-13.

13. Saunders LL, Krause JS. Behavioral factors related to fatigue among persons with spinal cord injury. Arch Phys Med Rehabil. 2012;93:313-18.
14. Li C, DiPiro ND, Krause J. A latent structural equation model of risk behaviors and pressure ulcer outcomes among people with spinal cord injury. Spinal Cord. 2017;55:553-8.

15. Li C, DiPiro ND, Krause J. A latent structural equation model of protective behaviors and pressure ulcer outcomes among people living with spinal cord injury. Spinal Cord. 2017;55:135-40.

16. Krause JS, Zhai Y, Saunders LL, Carter RE. Risk of mortality after spinal cord injury: an 8-year prospective study. Arch Phys Med Rehabil. 2009;90:1708-15.

17. Krause JS, Broderick L. Patterns of recurrent pressure ulcers after spinal cord injury: identification of risk and protective factors 5 or more years after onset. Arch Phys Med Rehabil. 2004;85:1257-64.

18. January AM, Zebracki K, Chlan KM, Vogel LC. Mental health and risk of secondary medical complications in adults with pediatric-onset spinal cord injury. Top Spinal Cord Inj Rehabil. 2014;20:1-12.

19. Saunders LL, Krause JS, Focht KL. A longitudinal study of depression in survivors of spinal cord injury. Spinal Cord. 2012;50:72-7.

20. Cao Y, Li C, Gregory A, Charlifue S, Krause JS. Depressive symptomatology after spinal cord injury: a multi-center investigation of multiple racial-ethnic groups. J Spinal Cord Med. 2017;40:85-92.

21. Davies DS, McColl MA. Lifestyle risks for three disease outcomes in spinal cord injury. Clin Rehabil. 2002;16:96-108.

22. January AM, Zebracki K, Czworniak A, Chlan KM, Vogel LC. Predictive factors of hospitalization in adults with pediatric-onset SCI: a longitudinal analysis. Spinal Cord. 2015;53:314-9.

23. Li C, Clark JM, Krause JS. Latent structural analysis of health outcomes in people living with spinal cord injury. Arch Phys Med Rehabil. 2017. https://doi.org/10.1016/j.apmr.2017.04.025.

24. Krause JS, Saunders LL. Risk and protective factors for secondary conditions: a 15-year longitudinal study. Top Spinal Cord Inj Rehabil. 2010;16:22-9.

25. CDC. Behavioral Risk Factor Surveillance System. 2010. http:// www.cdc.gov/brfss/questionnaires/pdf-ques/2010brfss.pdf. Accessed 22 Aug 2012.

26. Humeniuk R, Ali R, Babor TF, Farrell M, Formigoni ML, Jittiwutikarn J, et al. Validation of the Alcohol, Smoking and Substance Involvement Screening Test (ASSIST). Addiction. 2008;103:1039-47.

27. Whiteneck GG, Charlifue SW, Gerhart KA, Overholser JD, Richardson GN. The Craig Handicap Assessment and Reporting Technique. Englewood, CO: Craig Hospital; 1992.

28. Whiteneck GG, Charlifue SW, Gerhart KA, Overholser JD, Richardson GN. Quantifying handicap: a new measure of longterm rehabilitation outcomes. Arch Phys Med Rehabil. 1992;73:519-26.

29. SAS for Windows[computer program]. Version 9.4. Cary, NC: SAS Institute; 2015.

30. Muthen LK, Muthen BO. Mplus User's Guide. 7th ed. Los Angeles, CA: Muthen \& Muthen; 2015.

31. Browne, Cudeck R. Alternative ways of assessing model fit. In: Bollen K, Long S, editors. Testing Structural Equation Models. Beverly Hills, CA: Sage; 1993. p. 136-62.

32. Jamal A, King BA, Neff LJ, Whitmill J, Babb SD, Graffunder CM. Current Cigarette Smoking Among Adults - United States, 2005-2015. MMWR Morb Mortal Wkly Rep. 2016;65:1205-11.

33. Kanny D, Liu Y, Brewer RD, Lu H, Centers for Disease C, Prevention. Binge drinking - United States, 2011. MMWR Suppl. 2013;62:77-80.

34. van der Scheer JW, Martin Ginis KA, Ditor DS, Goosey-Tolfrey VL, Hicks AL, West CR et al. Effects of exercise on fitness and health of adults with spinal cord injury: A systematic review. Neurology. 2017;89:736-45. 
35. Geneen LJ, Moore RA, Clarke C, Martin D, Colvin LA, Smith BH. Physical activity and exercise for chronic pain in adults: an overview of Cochrane Reviews. Cochrane Database Syst Rev. 2017;4:CD011279.

36. Martin Ginis KA, Jorgensen S, Stapleton J. Exercise and sport for persons with spinal cord injury. Am J Phys Med Rehabil. 2012;4: 894-900.
37. Ginis KA, Hicks AL, Latimer AE, Warburton DE, Bourne C, Ditor DS, et al. The development of evidence-informed physical activity guidelines for adults with spinal cord injury. Spinal Cord. 2011;49:1088-96.

38. Krause JS, Reed KS, McArdle JJ. A structural analysis of health outcomes after spinal cord injury. J Spinal Cord Med. 2010;33:22-32. 